\title{
Online dating is associated with sex addiction and social anxiety
}

\author{
YONI ZLOT, MAYA GOLDSTEIN, KOBY COHEN and AVIV WEINSTEIN*
}

Department of Behavioral Science, Integrative Brain and Cognition Center, Ariel University, Ariel, Israel

(Received: February 4, 2017; revised manuscript received: July 18, 2017; second revised manuscript received: December 5, 2017; third revised manuscript received: January 9, 2018; fourth revised manuscript received: January 25, 2018; accepted: July 28, 2018)

\begin{abstract}
Background and aims: There is an increasing use of the Internet for dating and sexual purpose. The aim of this study was to investigate the contribution of social anxiety and sensation seeking to ratings of sex addiction among those who use dating Internet sites. Methods: A total of 279 participants (128 males and 151 females), with overall mean age being 25 years $(S D=2.75)$ and age range of $18-38$, answered questionnaires on the Internet. Questionnaires included demographic details, Leibowitz Social Anxiety Scale, Zuckerman Sensation Seeking Scale, and Sexual Addiction Screening Test (SAST). Results: The users of Internet-dating applications showed higher scores on the SAST than non-users. Second, participants who had low scores of sex addiction had lower social anxiety scores than the participants with high scores of sexual addiction. There was no difference in sensation-seeking scores between participants with low and high scores of sexual addiction. Discussion and conclusions: The results of this study indicate that social anxiety rather than sensation seeking or gender is a major factor affecting the use of Internet-dating applications for obtaining sexual partners.
\end{abstract}

Keywords: dating applications, sex addiction, sensation seeking, social anxiety

\section{INTRODUCTION}

Sex addiction or hypersexual disorder is characterized by a compulsive need for instant gratification of sexual urges (Carnes, 2001). Several diagnostic criteria have been proposed for sexual addiction but have not been validated scientifically. A lack of empirical evidence on sexual addiction is the result of the disease's complete absence from versions of the Diagnostic and Statistical Manual of Mental Disorders (DSM). Empirical research on hypersexual behavior has increased in recent years and this has led to considerable interest in classifying it as a behavioral addiction (Karila et al., 2014). Sexual addiction encompasses a range of activities including excessive masturbation, online pornography, use of the Internet for cybersex resulting in widespread negative health, and psychological and economic consequences (Karila et al., 2014). Although there is growing interest in sexual addiction in research and clinical practice, it is not recognized as a psychiatric disorder by the fifth edition of DSM (DSM-5; American Psychiatric Association, 2013). There are few epidemiological studies and several proposals for diagnostic criteria and it is therefore difficult to estimate the prevalence of this phenomenon. The estimated prevalence of sexual addiction varies between $3 \%$ and $16.8 \%$ in different studies, whereas in most studies it is estimated between 3\% and 6\% in the adult general population (Karila et al., 2014). In a study investigating 2,450 individuals from the general public of Sweden, $12 \%$ of men and $6.8 \%$ of women were classified as hypersexual (Långström \& Hanson, 2006), whereas in the USA, prevalence of sex addiction was estimated as 3\%-6\% (Carnes, 1992).

Over the USA, $45 \%$ of Americans use applications on the cell phone and $7 \%$ of them use them for dating purpose (Smith \& Duggan, 2013). The authors specified that when they conducted their first study of online dating, the release of the iPhone was still 2 years in the future. Today more than half of all American adults are smartphone owners, and dating is conducted on the smartphone. Internet-dating applications are popular among people in their 20's until their mid-30's (Smith \& Duggan, 2013). Recently, there is an increasing use of Internet-dating applications on smartphones for sexual purpose, namely as a platform for getting sexual partners. We investigated the relationships between online dating and sexual addiction. Second, there is anecdotal and clinical evidence that individuals with sexual addiction similarly to drug-dependent individuals are doing so for sensation seeking and in pursuit of thrill or excitement (Fong, 2006; Perry, Accordino, \& Hewes, 2007). Therefore, the study investigated the role of sensation seeking among individuals who use online-dating applications. Finally, social anxiety has been associated with excessive use of the Internet (Shepherd \& Edelmann, 2005; Weinstein, Dorani, et al., 2015). We therefore investigated whether

\footnotetext{
* Corresponding author: Aviv Weinstein; Department of Behavioral Science, Integrative Brain and Cognition Center, Ariel University, Science Park, Ariel 40700, Israel; Phone: +972 3 9076555; Fax: +972 3 9066629; E-mails: avivwe@ariel.ac.il; avivweinstein@ yahoo.com
}

This is an open-access article distributed under the terms of the Creative Commons Attribution-NonCommercial 4.0 International License, which permits unrestricted use, distribution, and reproduction in any medium for non-commercial purposes, provided the original author and source are credited, a link to the CC License is provided, and changes - if any - are indicated. 
social anxiety contributes to sexual addiction among individuals who use online-dating applications. In view of growing evidence for sex differences in men and women who are sexually addicted (Weinstein, Zolek, Babkin, Cohen, \& Lejoyeux, 2015), both men and women were included in this study in order to examine sex differences among this population. It was hypothesized that sensation seeking, social anxiety, and sex would contribute to the variance of sexual addiction scores among individuals who use dating applications on the Internet with smartphones.

\section{METHODS}

\section{Participants}

A total of 284 participants were recruited to the study, but five participants did not fulfill inclusion criteria and were excluded. Participants were excluded for psychiatric disorders including a history of attention-deficit hyperactivity disorder (ADHD) that was treated with methylphenidate, neurological damage, taking medications that affect the CNS, neurological damage, infection that might the affect CNS (HIV, syphilis, and herpes), pregnancy, or age under 18 years. Inclusion criteria were age of 18-45 males and females who regularly use the Internet. The final sample included 279 participants, of which 128 were men (45.9\%) and 151 were women $(54.1 \%)$. Overall mean age was 25 years $(S D=2.75)$ and age range was $19-38$ years. The mean age of men was 25.75 years $(S D=2.83)$ and of women it was 24.5 years $(S D=2.55)$. Forty percent of the participants have used dating applications in the past and present and $60 \%$ have not. Among men, 50.8\% have used the dating applications and $49.2 \%$ have not used them. Among women, $68.2 \%$ have used the dating applications and $31.8 \%$ have not used them. Most of the participants defined themselves as heterosexuals $(89.2 \%)$, while $4.7 \%$ were gays and $5.7 \%$ were bisexuals. A major part of the current sample had academic or equivalent educational background $(70.2 \%)$ and the rest of the sample had at least 12 years of study. In addition, a minor part of the participants were unemployed $(30.1 \%)$, most of participants either worked in part-time positions $(48.7 \%)$, or in full-time jobs $(21.1 \%)$.

\section{Measures}

(1) Demographic questionnaire included items on sex, age, sexual orientation, marital status, type of living, religion, education, employment, and use of dating application.

(2) Liebowitz Social Anxiety Scale (Liebowitz, 1987) is a self-reporting questionnaire that measures fear and avoidance of social situations. It includes 24 items, of which 13 describe social situations (e.g., "looking at people you don't know very well in the eyes") and 11 describe performance anxiety (e.g., "urinating in a public bathroom"). For each item, subjects were requested to fill in two scales: (a) scale of anxiety or fear from 1 (not at all) to 4 (very much) and (b) ratings of avoidance of the situation ranged from 1 (never) to 4 (often). The questionnaire was validated by Heimberg (1999) showing Cronbach's $\alpha$ reliability of .951 . In this study, Cronbach's $\alpha$ was .96.

(3) Sensation Seeking Scale (SSS; Zuckerman, Kolin, Price, \& Zoob, 1964) includes 40 items where participants had to choose between two opposite items. There were four personality traits including: Disinhibition, Boredom Susceptibility, Thrill and Adventure Seeking, and Experience Seeking. The questionnaire was validated by Arnett (1994) showing Cronbach's $\alpha$ reliability of .83-.86. In this study, there was Cronbach's $\alpha$ of .80. Cronbach's $\alpha$ reliability for each subscale was $\alpha=.35$ for boredom susceptibility, $\alpha=.80$ for thrill and adventure seeking, $\alpha=.57$ for experience seeking, and $\alpha=.66$ for for disinhibition.

(4) Sexual Addiction Screening Test (SAST; Carnes, 1991) includes 25 items containing yes-no questions. There are four categories, namely Affect Disturbance (e.g., "Do you feel that your sexual behavior is not normal?"), Relationship Disturbance (e.g., "Has your sexual behavior ever created problems for you and your family?"), Preoccupation (e.g., "Do you often find yourself preoccupied with sexual thoughts?"), Loss of Control (e.g., "Have you made efforts to quit a type of sexual activity and failed?"), and Associated Features (history of abuse, parental sexual problems, and sexual abuse of minors). The questionnaire was validated by Hook, Hook, Davis, Worthington, and Penberthy (2010) showing Cronbach's $\alpha$ reliability of .85-.95. In this study, there was Cronbach's $\alpha$ of .80 . The SAST is not validated to present any categorical data, and it has been used as a continuous variable but not for categorization of sexually addicted individuals.

\section{Procedure}

The questionnaires were advertised online in social networks and forums that were dedicated for dating and sex. Participants answered questionnaires on the Internet. They were informed that the study investigates sex addiction and that the questionnaires will remain anonymous for research purpose.

\section{Statistical and data analyses}

The analysis of the results was performed on Statistical Package for Social Science and AMOS for windows v.21 (IBM Corp., Armonk, NY, USA).

Prior analysis of Kolmogorov-Smirnov test of normality was conducted for social anxiety, sensation seeking, and sexual addiction scores. Since sensation seeking and sex addiction scores were not normal distributed, these variables were root transformed. Data referring to sex, age, sexual orientation, marital status, type of living, religion, education, employment, and use of dating applications were analyzed using a Pearson's $\chi^{2}$ test.

The relationship between social anxiety and sex addiction was investigated using an analysis of variance with scores of social anxiety that were divided into four categories of scores, such as no sex addiction, minor sex addiction, 
medium sex addiction, and major sex addiction. Following post-hoc comparison, $t$-tests were used to compare social anxiety scores and sensation-seeking scores between all groups of participants.

\section{Ethics}

The study was approved by the Institutional Review Board (IRB, Helsinki Committee) of the University of Ariel. All participants signed an informed consent form.

\section{RESULTS}

Social anxiety scores were of medium average and normal distribution $($ mean $=1.84, S D=0.5)$, but scores on sensation seeking $($ mean $=55.52, S D=6.14)$ and sex addiction (mean $=4.59, S D=3.72$ ) questionnaires were asymmetrical and they were root transformed to enable normal distribution.

There were no effects of gender $[t(1,282)=0.75$, $p=\mathrm{NS}]$, education levels $[t(1,277)=0.68, \quad p=\mathrm{NS}]$, employment status $[t(2,279)=1.28, p=\mathrm{NS}]$, type of living $[t(1,280)=0.19, p=\mathrm{NS}]$, or age $(r=-.10, p=\mathrm{NS})$ on sexual addiction scores. In addition, there were no significant correlations between SSS subscales of disinhibition $(M=14.4, S D=2.4, r=.07, p=\mathrm{NS})$, thrill and adventure seeking $(M=15.5, S D=2.95, r=-.10, p=\mathrm{NS})$, and experience seeking $(M=15.18, S D=2.11, r=.04, p=\mathrm{NS})$ with SAST scores. However, positive correlation was found between boredom susceptibility $(M=13.16, S D=1.71)$ with the overall SAST score $(r=.10, p<.05)$.

Scores on the Sex Addiction Questionnaires indicated that 28 participants $(10 \%)$ showed no sex addiction, 101 participants $(36.2 \%)$ showed minor level of sex addiction, 52 participants $(18.6 \%)$ showed medium level of sex addiction, and 98 participants (35.1\%) showed a high level of sex addiction following criteria defined by Carnes (1991). In terms of sex addiction dimensions, 24 participants exhibited preoccupations, 9 participants showed loss of control and relationships disturbance, and 50 participants reported affect disturbances. Ninety percent of participants reported no sexual abuse in their past. Among females, $17.9 \%$ reported sexual abuse during childhood or adolescence, whereas among males the rate was much lower $(0.8 \%)$.

A comparison of sex addiction scores between those who used dating applications (mean $=5.15, S D=3.49$ ) and those who did not use (mean $=4.21, S D=3.83$ ) showed a significant between group difference in sex addiction scores $[t(1,277)=2.086, p<.05]$. Second, participants who had low scores of sex addiction had lower social anxiety scores than the participants with high scores of sexual addiction $[t(1,228)=-3.44, p<.01]$. Table 1 shows scores of social anxiety and sensation seeking in relation to sex addiction.

\section{DISCUSSION}

The results of this study indicate high ratings of sex addiction among those who used dating applications for sex purpose on the Internet. There was no interaction between ratings of sensation seeking and sexual addiction. Finally, we did not find sex differences in sex addiction among our sample, unlike our previous study on cybersex and pornography (Weinstein, Zolek, et al., 2015).

Previous studies showed other psychiatric comorbidities of sex addiction, including mood disorders, depression and anxiety (Garcia \& Thibaut, 2010; Mick \& Hollander, 2006; Semaille, 2009), social anxiety, dysthymia, ADHD (Bancroft, 2008), affect dysregulation (Weiss \& Samenow, 2010) and post-traumatic stress disorder (Carnes, 1991). Depression and anxiety are common to other behavioral addictions, such as pathological gambling (Lorains, Cowlishaw, \& Thomas, 2011), compulsive buying (Mueller et al., 2010; Weinstein, Mezig, Mizrachi, \& Lejoyeux, 2015), Internet addiction (Kaess et al., 2014; Ko et al., 2014; Weinstein, Dorani, et al., 2015), and exercise addiction (Weinstein, Maayan, \& Weinstein, 2015). It is unclear whether behavioral addictions are a maladaptive way of coping with depression or anxiety or that depressive and anxiety disorders occur as a consequence of behavioral addictions. A relationship between anxiety, depression, and future Internet addiction among South Korean males has been established (Cho, Sung, Shin, Lim, \& Shin, 2013) and an exacerbation of depression, hostility, and social anxiety in the process of acquiring Internet addiction among adolescents has been reported (Ko et al., 2014). On the contrary, depression, hostility, and social anxiety decreased in the process of remission. We did not find sex differences in sex addiction among our sample, unlike our previous study on cybersex and pornography (Weinstein, Zolek, et al., 2015). It is plausible that among the dating population on the Internet, there is more equality between men and women. It is also plausible that the sex stereotype, which men are more assertive and sexually compulsive, is not representative of the young generation that is more equal and liberal.

The virtual dating scene is easier and more accessible than the real world and it is full of new opportunities for a variety of people who are interested in relations for sexual purpose including those with sexual addiction. For example, one of the dating applications enables the user to find users of the application within a certain distance and that can be useful if you are traveling on a train looking for a sexual partner. Sex addiction on the Internet includes watching, downloading online shopping of pornography, or using chat rooms for role play and fantasy for adults (Cooper, Delmonico, Griffin-Shelley, \& Mathy, 2004; Weinstein, Zolek, et al., 2015; Young, 2008). The Internet is a safe venue for sexual explorations and sexual activity that are

Table 1. Scores of social anxiety [mean $(S D)]$ and sensation seeking [mean $(S D)]$ in relation to sex addiction

\begin{tabular}{lcccccc}
\hline High $(n=101)$ & Medium $(n=52)$ & Minor $(n=101)$ & None $(n=28)$ & Sex addiction levels & $F$-test $(F)$ & $p$ value \\
\hline Sex addiction levels & $1.73(0.47)$ & $1.72(0.41)$ & $1.84(0.49)$ & $1.98(0.55)$ & 5.28 & .001 \\
Sensation seeking & $56.85(6.79)$ & $57.89(5.85)$ & $59.73(6.64)$ & $58.35(6.03)$ & 1.59 & .190 \\
\hline
\end{tabular}

Note. $S D$ : standard deviation. 
physically safer than sexual activity in real life (Griffiths, 2012). Sex-addicted individuals have difficulties in controlling their urges and they have often history of drug, alcohol, and nicotine addiction (Karila et al., 2014), which has negative effects on their couple and family life (Schneider, 2003; Manning, 2006). Carnes (2001) argued that the Internet for sex addicts is like crack cocaine for psychostimulant abusers. Cooper et al. (2004) who were one of the pioneer groups of investigators of online sex addiction found that sex addicts could spend $11 \mathrm{hr}$ online per week and experience problems in other aspects of life. Others have not found an association between daily life problems and time spent online in pornographic sites. Finally, taking sexual risks (Bancroft et al., 2003; Bancroft \& Vukadinovic, 2004; Kalichman \& Rompa, 1995, 2001) and seeking sexual excitement (Kalichman \& Rompa, 1995; Zuckerman, 1979) are often associated with sexual impulsivity (Hoyle, Fefjar, $\&$ Miller, 2000). These constructs have been applied to behaviors associated with sexually transmitted disease, having multiple partners, unprotected sex, unplanned pregnancies, and psychoactive drug use (Hayaki, Anderson, \& Stein, 2006; Justus, Finn, \& Steinmetz, 2000; Lejuez, Simmons, Aklin, Daughters, \& Dvir, 2004; Teese \& Bradley, 2008; Seal \& Agostinelli, 1994). The results of the study indicate no interaction between sensation seeking and measures of sex addiction in those using dating applications. It is possible that the major drive in our participants was to reduce social anxiety rather than increase excitement or sensation seeking. Sexual addiction on the dating scene may be an attempt to get intimacy by people who have intimacy problems rather than get excited. It seems that users of online-dating applications are more socially inhibited and less impulsive risk-takers than the typical sex addict who operates in the pornography and reallife sex scene.

\section{Limitations}

This study used an Internet-based survey that has high anonymity but has control over reliability of the questionnaires. It is plausible that due to social pressure and fear, the participants were not completely honest or open about their answers. Second, we have not assessed the frequent use of the dating application and that may be a confounding variable.

\section{CONCLUSIONS}

This study attempted to add to our existing knowledge on sexual addiction, information about a modern mean of the modern age that is dating applications on the Internet using smartphones. It was found that social anxiety rather than sensation seeking is a major factor that contributes to sexual addiction among this population. There are still issues that should be clarified such as online dating among those having many sexual partners or lovers, populations, such as homosexual, lesbians and transgender individuals, and individuals in treatment for sex addiction such as sex anonymous. Other issues arising from the study are comorbidity with other psychiatric conditions, such as personality disorders (borderline, antisocial narcissistic, and others). Unlike drug and alcohol addiction, it seems difficult to avoid sexual activity as a model of treatment by abstinence; hence, treatment for sex addiction needs to consider the complexity and importance of the need to fulfill the sex drive in modern society.

Funding sources: The study was conducted as part of an academic course in behavioral addiction at the Ariel University, Ariel, Israel.

Authors' contribution: All individuals including the authors of the study have contributed substantially to the scientific process leading up to the writing of the paper. The authors have contributed to the conception and design of the project, performance of the experiments, analysis and interpretation of the results, and preparation of the manuscript for publication.

Conflict of interest: The authors have no interests or activities that might be seen as influencing the research (e.g., financial interests in a test or procedure and funding by pharmaceutical companies for research). They report no conflict of interest regarding this study.

Acknowledgements: The study was presented in the 3rd ICBA meeting in Geneva Switzerland in March 2016.

\section{REFERENCES}

American Psychiatric Association. (2013). Diagnostic and statistical manual of mental disorders $\left(D S M-5^{\circledR}\right)$. Washington, DC: American Psychiatric Association.

Arnett, J. (1994). Sensation seeking: A new conceptualization and a new scale. Personality and Individual Differences, 16(2), 289-296. doi:10.1016/0191-8869(94)90165-1

Bancroft, J. (2008). Sexual behavior that is "out of control": A theoretical conceptual approach. Psychiatric Clinics of North America, 31(4), 593-601. doi:10.1016/j.psc.2008.06.009

Bancroft, J., Janssen, E., Strong, D., Carnes, L., Vukadinovic, Z., \& Long, J. S. (2003). Sexual risk-taking in gay men: The relevance of sexual arousability, mood, and sensation seeking. Archives of Sexual Behavior, 32(6), 555-572. doi:10.1023/A:1026041628364

Bancroft, J., \& Vukadinovic, Z. (2004). Sexual addiction, sexual compulsivity, sexual impulsivity, or what? Toward a theoretical model. Journal of Sex Research, 41(3), 225-234. doi:10.1080/00224490409552230

Carnes, P. (1991). Sexual Addiction Screening Test. Tennessee Nurse, 54(3), 29.

Carnes, P. (1992). Don't call it love: Recovery from sexual addiction. Random House LLC: New York, NY.

Carnes, P. (2001). Out of the shadows: Understanding sexual addiction. Minneapolis, MN: CompCare.

Cho, S. M., Sung, M.-J., Shin, K. M., Lim, K. Y., \& Shin, Y. M. (2013). Does psychopathology in childhood predict Internet addiction in male adolescents? Child Psychiatry and Human Development, 44(4), 549-555. doi:10.1007/s10578-0120348-4 
Cooper, A. L., Delmonico, D. L., Griffin-Shelley, E., \& Mathy, R. M. (2004). Online sexual activity: An examination of potentially problematic behaviors. Sexual Addiction \& Compulsivity, 11(3), 129-143. doi:10.1080/10720160490882642

Fong, T. W. (2006). Understanding and managing compulsive sexual behaviors. Psychiatry, 3(11), 51-58.

Garcia, F. D., \& Thibaut, F. (2010). Sexual addictions. The American Journal of Drug and Alcohol Abuse, 36(5), 254-260. doi:10.3109/00952990.2010.503823

Griffiths, M. D. (2012). Internet sex addiction: A review of empirical research. Addiction Research \& Theory, 20(2), 111-124. doi:10.3109/16066359.2011.588351

Hayaki, J., Anderson, B., \& Stein, M. (2006). Sexual risk behaviors among substance users: Relationship to impulsivity. Psychology of Addictive Behaviors, 20(3), 328-332. doi:10.1037/ 0893-164X.20.3.328

Heimberg, R. G., Horner, K. J., Juster, H. R., Safren, S. A., Brown, E. J., Schneier, F. R., \& Liebowitz, M. R. (1999). Psychometric properties of the Liebowitz Social Anxiety Scale. Psychological Medicine, 29(1), 199-212.

Hook, J. N., Hook, J. P., Davis, D. E., Worthington, E. L., Jr., \& Penberthy, J. K. (2010). Measuring sexual addiction and compulsivity: A critical review of instruments. Journal of Sex \& Marital Therapy, 36(3), 227-260. doi:10.1080/ 00926231003719673

Hoyle, R. H., Fejfar, M. C., \& Miller, J. D. (2000). Personality and sexual risk taking: A quantitative review. Journal of Personality, 68(6), 1203-1231. doi:10.1111/1467-6494.00132

Justus, A. N., Finn, P. R., \& Steinmetz, J. E. (2000). The influence of traits of disinhibition on the association between alcohol use and risky sexual behavior. Alcoholism: Clinical and Experimental Research, 24(7), 1028-1035. doi:10.1111/ j.1530-0277.2000.tb04646.x

Kaess, M., Durkee, T., Brunner, R., Carli, V., Parzer, P., Wasserman, C., Sarchiapone, M., Hoven, C., Apter, A., Balazs, J., Balint, M., Bobes, J., Cohen, R., Cosman, D., Cotter, P., Fischer, G., Floderus, B., Iosue, M., Haring, C., Kahn, J. P., Musa, G. J., Nemes, B., Postuvan, V., Resch, F., Saiz, P. A., Sisask, M., Snir, A., Varnik, A., Žiberna, J., \& Wasserman, D. (2014). Pathological Internet use among European adolescents: psychopathology and self-destructive behaviours. European Child \& Adolescent Psychiatry, 23(11), 1093-1102. doi:10.1007/s00787-014-0562-7

Kalichman, S. C., \& Rompa, D. (1995). Sexual sensation seeking and sexual compulsivity scales: Validity, and predicting HIV risk behavior. Journal of Personality Assessment, 65(3), 586-601. doi:10.1207/s15327752jpa6503_16

Kalichman, S. C., \& Rompa, D. (2001). The sexual compulsivity scale: Further development and use with HIV-positive persons. Journal of Personality Assessment, 76(3), 379-395. doi:10.1207/S15327752JPA7603_02

Karila, L., Wéry, A., Weinstein, A., Cottencin, O., Petit, A., Reynaud, M., \& Billieux, J. (2014). Sexual addiction or hypersexual disorder: Different terms for the same problem? A review of the literature. Current Pharmaceutical Design, 20(25), 4012-4020. doi:10.2174/13816128113199 990619

Ko, C.-H., Liu, T.-L., Wang, P.-W., Chen, C.-S., Yen, C.-F., \& Yen, J.-Y. (2014). The exacerbation of depression, hostility, and social anxiety in the course of Internet addiction among adolescents: A prospective study. Comprehensive
Psychiatry, 55(6), 1377-1384. doi:10.1016/j.comppsych. 2014.05.003

Långström, N., \& Hanson, R. K. (2006). High rates of sexual behavior in the general population: Correlates and predictors. Archives of Sexual Behavior, 35(1), 37-52. doi:10.1007/ s10508-006-8993-y

Lejuez, C. W., Simmons, B. L., Aklin, W. M., Daughters, S. B., \& Dvir, S. (2004). Risk-taking propensity and risky sexual behavior of individuals in residential substance use treatment. Addictive Behaviors, 29(8), 1643-1647. doi:10.1016/j. addbeh.2004.02.035

Liebowitz, M. R. (1987). Social phobia. Modern Problems of Pharmacopsychiatry, 22, 141-173. doi:10.1159/000414022

Lorains, F. K., Cowlishaw, S., \& Thomas, S. A. (2011). Prevalence of comorbid disorders in problem and pathological gambling: Systematic review and meta-analysis of population surveys. Addiction, 106(3), 490-498. doi:10.1111/ j.1360-0443.2010.03300.x

Manning, J. C. (2006). The impact of Internet pornography on marriage and the family: A review of the research. Sexual Addiction \& Compulsivity, 13(2-3), 131-165. doi:10.1080/ 10720160600870711

Mick, T. M., \& Hollander, E. (2006). Impulsive-compulsive sexual behavior. CNS Spectrums, 11(12), 944-955. doi:10.1017/ S1092852900015133

Mueller, A., Mitchell, J. E., Black, D. W., Crosby, R. D., Berg, K., \& de Zwaan, M. (2010). Latent profile analysis and comorbidity in a sample of individuals with compulsive buying disorder. Psychiatry Research, 178(2), 348-353. doi:10.1016/ j.psychres.2010.04.021

Perry, M., Accordino, M. P., \& Hewes, R. L. (2007). An investigation of Internet use, sexual and nonsexual sensation seeking, and sexual compulsivity among college students. Sexual Addiction \& Compulsivity, 14(4), 321-335. doi:10.1080/ 10720160701719304

Schneider, J. (2003). The impact of compulsive cybersex behaviours on the family. Sexual and Relationship Therapy, 18(3), 329-354. doi:10.1080/146819903100153946

Seal, D. W., \& Agostinelli, G. (1994). Individual differences associated with high-risk sexual behaviour: Implications for intervention programmes. Aids Care, 6(4), 393-397. doi:10.1080/09540129408258653

Semaille, P. (2009). The new types of addiction. Revue Medicale de Bruxelles, 30(4), 335-357.

Shepherd, R.-M., \& Edelmann, R. J. (2005). Reasons for Internet use and social anxiety. Personality and Individual Differences, 39(5), 949-958. doi:10.1016/j.paid.2005.04.001

Smith, A., \& Duggan, M. (2013). Online dating \& relationships. Washington, DC: Pew Research Center Internet and Technology.

Teese, R., \& Bradley, G. (2008). Predicting recklessness in emerging adults: A test of a psychosocial model. The Journal of Social Psychology, 148(1), 105-128. doi:10.3200/ SOCP.148.1.105-128

Weinstein, A., Dorani, D., Elhadfi, R., Bukovza, Y., Yarmulnik, A., \& Dannon, P. (2015). Internet addiction is associated with social anxiety in young adults. Annals of Clinical Psychiatry, 27(1), 4-9. doi:10.1093/med/9780199380183. 003.0001

Weinstein, A., Maayan, G., \& Weinstein, Y. (2015). A study on the relationship between compulsive exercise, depression and 
anxiety. Journal of Behavioral Addictions, 4(4), 315-318. doi:10.1556/2006.4.2015.034

Weinstein, A., Mezig, H., Mizrachi, S., \& Lejoyeux, M. (2015). A study investigating the association between compulsive buying with measures of anxiety and obsessive-compulsive behavior among Internet shoppers. Comprehensive Psychiatry, 57, 46-50. doi:10.1016/j.comppsych.2014.11.003

Weinstein, A. M., Zolek, R., Babkin, A., Cohen, K., \& Lejoyeux, M. (2015). Factors predicting cybersex use and difficulties in forming intimate relationships among male and female users of cybersex. Frontiers in Psychiatry, 6(5), 1-8. doi:10.3389/ fpsyt.2015.00054
Weiss, R., \& Samenow, C. P. (2010). Smart phones, social networking, sexting and problematic sexual behaviors A call for research. Sexual Addiction \& Compulsivity, 17(4), 241-246. doi:10.1080/10720162.2010.532079

Young, K. S. (2008). Internet sex addiction risk factors, stages of development, and treatment. American Behavioral Scientist, 52(1), 21-37. doi:10.1177/0002764208321339

Zuckerman, M. (1979). Sensation seeking: Beyond the optimal level of arousal. Hillsdale, NJ: Lawrence Erlbaum Associates.

Zuckerman, M., Kolin, E. A., Price, L., \& Zoob, I. (1964). Development of a Sensation-Seeking Scale. Journal of Consulting Psychology, 28(6), 477-482. doi:10.1037/h0040995 